\title{
Mid-year review: physical inactivity universally accepted as the biggest public health problem of the 21st century, shoulder exam challenges, and progress against the scourges of anterior knee pain and ACL injuries
}

\author{
K M Khan
}

As the northern hemisphere embarks on various degrees of summer stupor, and the southern hemisphere weathers the winter with a crowd of football codes, I take this chance to alert you to what many have considered highlights of the year to date.

\section{EXERCISE IS MEDICINE (AND SO IS PHYSICAL ACTIVITY)}

Professor Steven Blair opened BJSM's year by announcing a "surge" against physical inactivity. ${ }^{1}$ Interestingly there has been no push-back against Professor Blair's powerful argument and compelling data. How time flies when I consider that Dr Frank Booth's classic declaration of war against physical inactivity was in 2000_almost a decade ago! ${ }^{2}$

Now is the time to redouble our efforts to promote physical activity as the single most useful health modality. We also need to be cohesive so that lawmakers are not confused by multiple messages or by competing interests. To this end, BJSM fully endorses the American College of Sports Medicine's Exercise is Medicine initiative (http://www.exerciseismedicine.org/). In addition to key papers in $B J S M,{ }^{1}{ }^{3} 4$ particularly in the January and February theme issues, please check out the exciting news in this issue of BJSM. New data show that 50-year-old men can obtain a new "lease of life" with just 10 years of increased physical activity. ${ }^{5}$ Specifically, a decade of physical activity from 50 years on means that the person's risk of death is no higher than that of a

Correspondence to: Dr K Khan, The University of British Columbia, Centre for Hip Health and Mobility, Suite 320-5950 University Blvd, Vancouver V6T 1Z3, Canada; karim.khan@ubc.ca long-term exerciser! It's clearly not too late at 50! Tell your patients about this, frame the one-page PDF in your waiting room. And if you are 50, it's time to increase your activity!

\section{SHOULDER EXAMINATION}

The shoulder exam continues to be a challenge for many clinicians but this month BJSM can provide a video link to Dr Mark Hutchinson's shoulder exam (http://bjsm.bmj.com). This is an ideal learning opportunity for younger clinicians and those young at heart. However, having become skilled, remember the limitations! Dr Eric Hegedus and colleagues from Duke University really challenged the utility of the "classic" orthopaedic shoulder tests; for example the authors claim that the diagnostic accuracy of the Neer test for impingement, the Hawkins-Kennedy test for impingement and the Speed test for labral pathology is limited. ${ }^{6}$ Also on shoulders-please note the 1 September deadline for the special shoulder pain issue of January 2010. And kudos to Dr Hutchinson, his knee examination video has been downloaded over 300000 times! The McMurray's test section alone has been clicked 50000 times!

\section{ANTERIOR KNEE PAIN}

In March 2009, we published a cover story relating to orthoses and knee pain.? Prefabricated foot orthoses were superior to flat inserts in the short term management of patellofemoral pain syndrome-orthotics can work! There was no differences between the effects of foot orthoses and physiotherapy, nor was there any benefit of adding foot orthoses to physiotherapy. ${ }^{7}$ Considering that all treatment groups showed clinically meaningful long term improvements, GPs may do some patients a favour by prescribing foot orthoses. In this issue (see p 503) Denmark's Henriksen and colleagues examine the effect of pain on joint function. ${ }^{8}$ This has major implications for management of patellofemoral pain.

\section{ACL PREVENTION}

Congratulations to both our Finnish and Norwegian colleagues for their terrific papers in BMJ (with BJSM transfer!) highlighting that neuromuscular training programmes prevent major injuries..$^{9} 10$ Also, in the past two issues Professor Timothy Hewett provided insights into when anterior cruciate ligament (ACL) injury may be most likely to occur-when a valgus knee force combined with trunkal sway places the ACL under enormous strain. ${ }^{11}{ }^{12}$ And don't forget the ACLrelated podcast already on the home page and keep an eye out for regular podcasts there. When you are at the lake/cabin/ resort or other holiday destination, please do feel free to use the spare time to let us know how BJSM could serve you better! And don't forget to set an example that physical activity is medicine!

\section{SPECIAL INTERNATIONAL OLYMPIC COMMITTEE SUPPORTED THEME ISSUE: SUDDEN CARDIAC DEATH}

$B J S M^{\prime}$ 's themed issues focusing on injury prevention and health protection begin in September 2009. The first is dedicated to sudden cardiac death in athletes. Subsequent editions will appear quarterly in print and online. These Injury Prevention and Health Protection issues will be sent to BJSM subscribers, as well as all 205 National Olympic Committees and more than 35 major sports federations.

Competing interests: None.

Br J Sports Med 2009;43:469-470.

doi:10.1136/bjsm.2009.062794

\section{REFERENCES}

1. Blair SN. Physical inactivity: the biggest public health problem of the 21st century. Br J Sports Med 2009;43:1-2.

2. Booth FW, Gordon SE, Carlson CJ, et al. Waging war on modern chronic diseases: primary prevention through exercise biology. J Appl Physiol 2000;88:774-87.

3. Church TS, Blair SN. When will we treat physical activity as a legitimate medical therapy even though it does not come in a pill? Br J Sports Med 2009:43:80-1.

4. Sallis RE. Exercise is medicine and physicians need to prescribe it! Br J Sports Med 2009;43:3-4.

5. Byberg L, Melhus H, Gedeborg R, et al. Total mortality after changes in leisure time physical activity in 50 year old men: 35 year follow-up of population based cohort. BMJ 2009:338:b688. 
6. Hegedus EJ, Goode A, Campbell S, et al. Physical examination tests of the shoulder: a systematic review with meta-analysis of individual tests Br J Sports Med 2008:42:80-92.

7. Collins N, Crossley K, Beller E, et al. Foot orthoses and physiotherapy in the treatment of patellofemoral pain syndrome: randomised clinical trial. $\mathrm{Br} J$ Sports Med 2009;43:163-8.

8. Henriksen M, Alkjær T, Simonsen EB, et al.

Experimental muscle pain during a forward lunge - the effects on knee joint dynamics and electromyographic activity. Br J Sports Med 2009:43:503-7.

9. Pasanen K, Parkkari J, Pasanen M, et al. Neuromuscular training and the risk of leg injuries in female floorball players: cluster randomised controlled study. BMJ 2008;337:a295.

10. Soligard T, Myklebust G, Steffen K, et al. Comprehensive warm-up programme to prevent injuries in young female footballers: cluster randomised controlled trial. BMJ 2008;337:a2469.
11. Quatman CE, Hewett TE. The anterior cruciate ligament injury controversy: is "valgus collapse" a sex-specific mechanism? Br J Sports Med 2009;43:328-35.

12. Hewett TE, Torg JS, Boden BP. Video analysis of trunk and knee motion during non-contact anterior cruciate ligament injury in female athletes: lateral trunk and knee abduction motion are combined components of the injury mechanism. Br J Sports Med 2009:43:417-22. 